\title{
Damage Effect in the Fracture Toughness of Nodular Cast Iron
}

\author{
M.J. Dong, C. Berdin, A.S. Beranger* and C. Prioul \\ Laboratoire MSS/MAT, URA 850 du CNRS, Ecole Centrale Paris, 92295 Châtenay-Malabry, France \\ * Renault Automobiles, Direction de la Recherche, Service 60152, 860 Quai de Stalingrad, \\ 92109 Boulogne-Billancourt, France
}

\begin{abstract}
In order to understand the toughness of nodular cast iron, the flow stress have been studied numerically by using Gurson's model considering that nodular cast iron can be regarded as a porous material. The damaged zone ahead of the crack tip is studied by SEM observations on the pre-polished surface of a CT 25 specimen, before and after ductile tearing. It is shown that the damaged zone is very large in the GGG 40 nodular cast iron (through almost the whole ligament ahead of the crack), so the Linear Elastic Fracture Mechanics is not valid in nodular cast iron for small specimens. The force versus crack opening displacement curves calculated in $2 \mathrm{D}$ for plane strain and plane stress conditions give respectively an upper and a lower limit as compared with the experimental curve. Only 3D calculations lead to a good fit with the experimental curve. This result shows that the stress state ahead of the crack tip of a nodular cast iron is intermediate between plane stress and plane strain conditions, due to the high density of voids inside the damaged material.
\end{abstract}

\section{Introduction}

Nodular cast iron is an important engineering material which exhibits a high ductility and can offer some economic advantages over usual steels. It is used extensively for structural strength parts and for security parts for which fracture toughness is a major concern (e.g. turbine casings, automotive components, transportation and storage casks for radioactive materials $[1,2])$, which may reach a 100 ton weight with a wall thickness greater than $30 \mathrm{~cm}$ [3] and in car manufacturing which require thin walls (a few mm thick) and complex shapes.

A large amount of research has been conducted to determine the fracture toughness of cast iron [4-7]. From a Linear Elastic Fracture Mechanics (LEFM) approach, Nanstad et al. [7-11] concluded that, unlike usual materials, the fracture toughness $\mathrm{K}_{\mathrm{Q}}$ of nodular cast iron increases with the specimen thickness. By using the Elastic-Plastic Fracture Mechanics (EPFM) approach, with the single specimen tests on Compact Tension specimens, the $\mathrm{KJc}$ values appear to be dependent on the percentage of the unloading performed to monitor crack extension [12-14].

The aim of the present work is to get a better understanding of the toughness increase with specimen thickness. Therefore, the damaged zone ahead of the crack tip has been examined experimentally after stable crack propagation, by SEM observations of the surface of a pre-polished CT 25 specimen. From these observations as well as in-situ tensile test results, nodular cast iron can be regarded as a porous material. The modified Gurson's model, introduced into a Finite Element code is shown to give a precise modelling of the stress-strain behavior of both smooth and notched specimens. From this validation, a numerical modelling of the load versus crack opening displacement is realised for CT 25 and CT 125 specimens, thus allowing a comparative study of $2 \mathrm{D}$ and $3 \mathrm{D}$ results. The validity for cast iron of the experimental methods usually applied to define crack initiation is also discussed.

\section{Material}

\subsection{Chemical composition}

The global chemical composition of the material studied, which is a GGG40 ferritic cast iron (German norm) has been reported in Table 1. X Ray microprobe chemical analysis showed that Silicon and 
Manganese content of the matrix were respectively $2.6 \%$ and $0.2 \%$, with an homogeneous distribution. Micrographic observation of the material reveals that the matrix is fully ferritic. More detailed image analysis (realised on Cambridge LQ 500 Image analyser) showed that the volume fraction of graphite is $7.7 \%$.

Table 1 : Global chemical composition (Weight \%) of the GGG 40 nodular ferritic cast iron.

\begin{tabular}{|c|c|c|c|c|c|c|c|c|c|}
\hline & $\mathrm{C}$ & $\mathrm{Si}$ & $\mathrm{Mn}$ & $\mathrm{S}$ & $\mathrm{P}$ & $\mathrm{Mg}$ & $\mathrm{Cu}$ & $\mathrm{Ni}$ & $\mathrm{Cr}$ \\
\hline GGG40 & 3.35 & 2.25 & 0.3 & 0.006 & 0.025 & 0.039 & 0.06 & 0.04 & 0.02 \\
\hline
\end{tabular}

\subsection{Tensile properties}

Tensile tests were performed on a $100 \mathrm{kN}$ screw driven INSTRON machine with a $610^{-3} \mathrm{~s}^{-1}$ strain rate, unless otherwise stated. The tensile specimens were $5 \mathrm{~mm}$ in diameter with a $30 \mathrm{~mm}$ gauge length. The notched specimen was an axisymmetric AE4 specimen (diameter : $10 \mathrm{~mm}$; notch radius: $4 \mathrm{~mm}$ ).

Table 2 summarises the mechanical properties of this cast iron which will be analysed further on in the light of flow stress modelling.

Table 2 : Mechanical properties (tensile test $\dot{\varepsilon}=610^{-3} \mathrm{~s}^{-1}$ )

\begin{tabular}{|c|c|c|c|c|}
\hline & E (GPa) & $\sigma_{y}(\mathrm{MPa})$ & $\sigma_{\text {UTS }}(\mathrm{MPa})$ & A\% \\
\hline GGG40 & 187 & 260 & 393 & 23 \\
\hline
\end{tabular}

\section{I.3 Fracture toughness}

The influence of specimen thickness on the fracture toughness of GGG 40 has already been studied by Brouard et al. [17]. From this study, we have reported respectively in figures $1 \mathrm{a}, \mathrm{b}, \mathrm{c}$ the evolution of the load versus the crack mouth opening displacement (CMOD) for CT 125, CT 50 and CT 24 specimens. Using these experimental results, the $\mathrm{J}_{\mathrm{C}}$ values, obtained from different methods (one-specimen method: $P_{Q}$ or $P_{\max }$; or multiple-specimen method : $P_{\mathrm{I}}$ ), can be plotted versus specimen thickness (fig. 2, after [17]). The corresponding crack opening displacements at initiation $(\Delta \mathrm{u})$ are given in table 3 [after 17]. It appears that in small CT 24 specimens, $\mathrm{PQ}<\mathrm{PI}<\mathrm{P}_{\max }$, whereas in larger specimens $\mathrm{PQ}=\mathrm{PI}_{\mathrm{I}}<\mathrm{P}_{\max }$. Therefore, in cast iron, the measured fracture toughness is strongly dependent on the method used for the determination of $\mathrm{J}_{\mathrm{C}}$, due to the influence of the specimen thickness on the load versus CMOD curve (see Fig, 1)

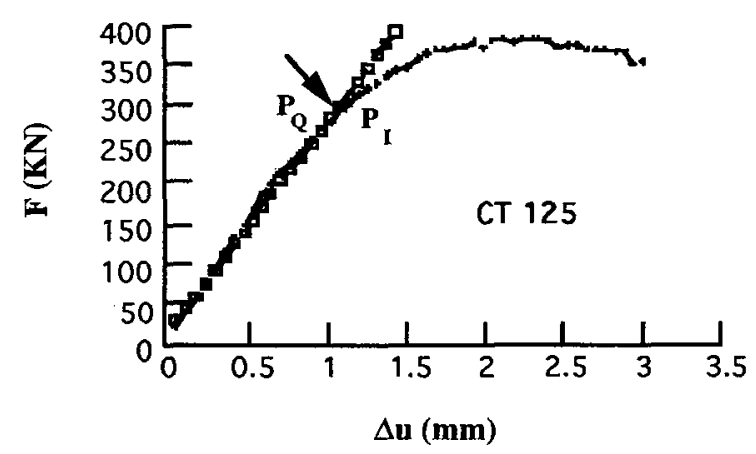

a)

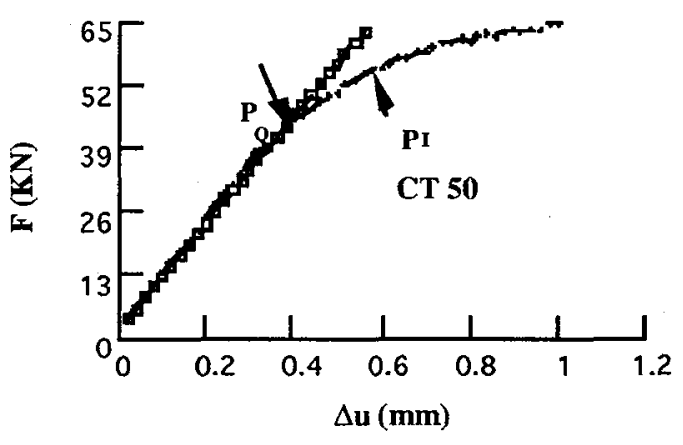

b) 


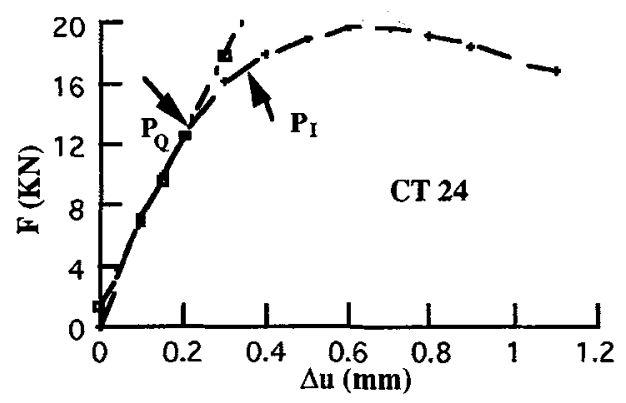

c)

Fig. 1 - Load versus crack opening displacement in CT 24, CT 50 and CT 125 specimens [17]

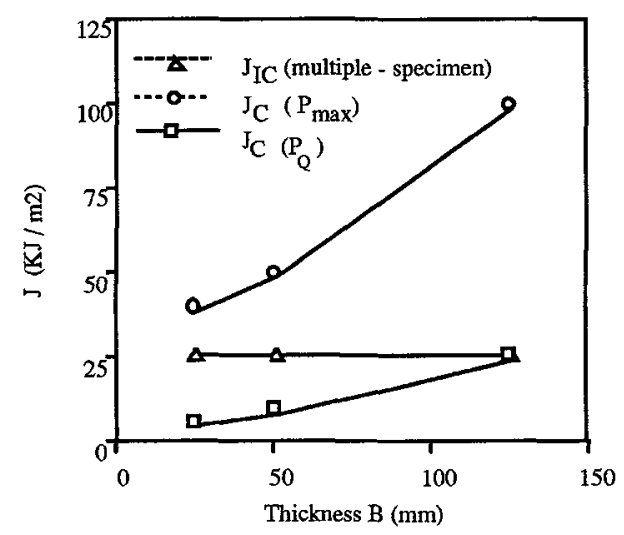

Fig. 2 - Fracture toughness of GGG 40 cast iron versus specimen thickness, as measured by different methods [17]

Table 3. Values of $\Delta \mathrm{u}$ for different conventional definitions of the fracture toughness [17]

\begin{tabular}{|c|c|c|c|}
\hline$\Delta \mathrm{u}(\mathrm{mm})$ & CT 24 & CT 50 & CT 125 \\
\hline $\mathrm{P}_{\max }$ & 0.72 & 0.8 & 1.96 \\
\hline $\mathrm{P}_{\mathrm{I}}($ multiple-specimen) & 0.4 & 0.6 & 0.9 \\
\hline $\mathrm{PQ}_{\mathrm{P}}$ & 0.2 & 0.4 & 1 \\
\hline
\end{tabular}

\section{Damage characterisation}

\section{II.1 Damage mechanisms}

Using a Scanning Electron Microscope, equipped with an in situ tensile test machine, damage evolution can be observed on the surface of the specimen, from its nucleation to the final rupture step. Since a full description of the damage mechanisms is given in previous papers [15,16], only the more significant results are reported here : most of the graphite nodules are debonded from the matrix in the very early stage of the macroscopic yielding. The critical stress for interface debonding is about $80 \mathrm{MPa}$ [15]. Flow stress modelling of cast iron confirms that graphite nodules serve essentially as void nucleation sites and that as soon as debonding occurs, when macroscopic yielding occurs, nodules can be replaced by voids [16]. 


\section{II.2. Damaged zone size ahead of the crack tip}

A CT-25 specimen was used to study the damaged zone ahead of the crack tip. At first, the two lateral surfaces of the CT-25 specimen (figure 3 ) are polished before straining, with a final $1 / 4 \mu \mathrm{m}$ diamond powder polishing. Then reference marks are made on the surface by mean of microhardness indentations to define square grids $4 \mathrm{~mm} \times 4 \mathrm{~mm}$ large (figure 3 ). This facilitates following up nodule interface modifications before and after ductile tearing. The fatigue precrack is then made on a MTS machine, using the following conditions: loading ratio: $R=0.105$; maximum load: $P_{\max }=8100 \mathrm{~N}$; test frequency : 20 cycles/s ; number of cycles : 4570 . SEM observations are made before and after pre-cracking (1.3 $\mathrm{mm})$ in order to select the nodules which will be observed and to verify the absence of initial damage. The tear test is made on an INSTRON machine with an imposed speed of $10^{-4} \mathrm{~m} / \mathrm{s}$ applied at point B (Fig. 3). The crack opening displacement is limited to $\Delta \mathrm{u}=0.4 \mathrm{~mm}$, which corresponds to a stable crack propagation $(\Lambda \mathrm{a}=0.8 \mathrm{~mm})$ [17]. Finally, SEM observations are made to determine the damaged zone, which is defined as the area inside which graphite nodule interface decohesions are observed. As illustrated in figure 3 , the damaged zone extension is very large (through almost the whole ligament ahead of the crack) [15].

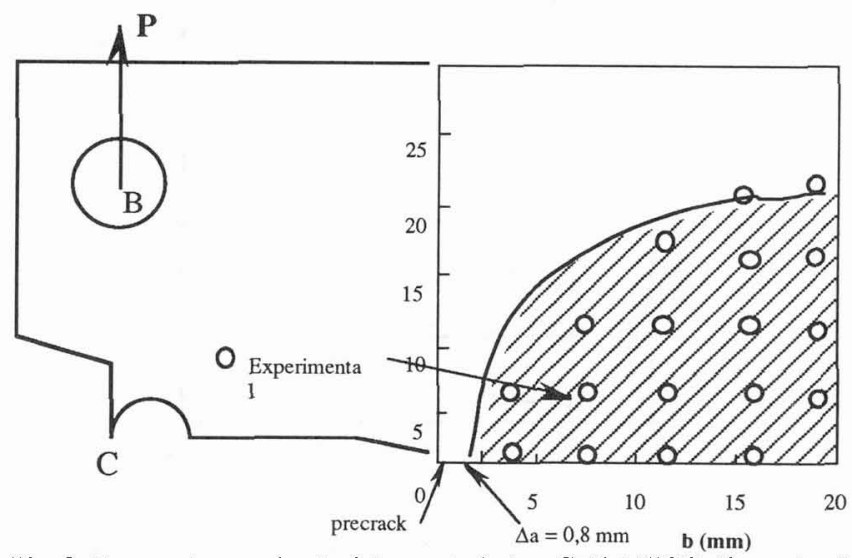

Fig. 3. Damaged zone ahead of the crack tip in a CT 25 (GGG 40 cast iron)

\section{Modelling of the stress strain behaviour}

\section{III.1 Modelling procedure}

Since damage observations have shown that the debonding of the interface between the graphite nodules and the ferritic matrix coincides with the macroscopic yielding of cast iron, it can be concluded that cast iron behaves essentially as a porous material. Consequently the modified Gurson's model, implemented in a finite element code (Zebulon, developed by Ecole des Mines de Paris), was used to model the stress strain behaviour of smooth specimen as well as the load versus reduction of diameter curves for notched specimens.

\section{III.1.1 Yield function}

Tvergaard's modification of Gurson's yielding condition is used $[18,19]$ :

$$
\begin{aligned}
& \phi(\sigma)=\frac{\sigma_{\mathrm{eq}}^{2}}{\mathrm{Y}^{2}}+2 \mathrm{f}^{*} \mathrm{q}_{1} \cosh \left(\frac{3}{2} \mathrm{q}_{2} \frac{\sigma_{\mathrm{m}}}{\mathrm{Y}}\right)-\left[1+\left(\mathrm{q}_{1} \mathrm{f}^{*}\right)^{2}\right]=0 \\
& f^{*}=f \quad f<f_{C} \\
& f^{*}=f_{c}+f_{c}\left(f-f_{c}\right) \quad f>f_{C} \quad q_{1}=1.5 \text { and } q_{2}=1
\end{aligned}
$$

$\sigma_{\mathrm{eq}}:$ Von Mises equivalent stress $\quad \sigma_{\mathrm{m}}$ : hydrostatic stress $\quad \mathrm{f}$ : void volume fraction $\mathrm{Y}$ : flow stress of the matrix $\mathrm{f}_{\mathrm{C}}$ : critical void volume fraction at void coalescence 
Generally, both the nucleation of new voids and growth of existing voids contribute to the increase of the volume fraction of voids, so the growth rate can be expressed as :

$$
\dot{\mathrm{f}}=\dot{\mathrm{f}}_{\text {growth }}+\dot{\mathrm{f}}_{\text {nucleation }}
$$

\section{III.1.2 Damage parameter}

In agreement with our experimental observations, it is assumed that all the nodules can be initially replaced by voids and that nucleation of new voids can be neglected. Consequently, the growth rate of the initial cavities is only considered.

The graphite nodule volume fraction determined by image analysis was therefore used as the initial void volume in the numerical simulation, $f_{0}=0.077$. The value of $f_{c}$, equal to 0.12 , and the value of the void volume fraction $f$ at fracture, equal to 0.2 , were determined from the evolution of the damage parameter given by modulus measurements [16].

\section{III.2 Constitutive equations of the material}

The constitutive equation of the ferritic matrix was chosen as the one of a Fe-2.6 Si steel, which composition is close to that of the ferritic matrix as determined by X Ray microprobe quantitative analysis. The corresponding elastoplastic stress strain behaviour, represented in figure 4, was obtained by linear interpolation of the stress strain curve for pure iron and that given in the literature for the $\mathrm{Fe}-3 \% \mathrm{Si}$ alloy [24]. Nevertheless, using this law at the microscopic level is questionable, since it has been established from the macroscopic behaviour of ferrite. This is especially the case for the early stage of the plastic deformation ("easy glide" plateau) which is associated to Lüders band heterogeneous plastic deformation. The length of this plateau corresponds to the propagation of Lüders band along the whole size of the specimen. The stress value in the plateau corresponds to plasticity propagation, stabilised by grain boundary crossing by slip bands. In cast iron or porous iron there exists an important stress localisation near particles or voids. This localisation favours the triggering of plastic deformation at several points in the matrix at the micro scale level. In this case, the Lüders bands, if existing, are limited by nodules or pores, so they cannot extent all across the specimen and the easy glide plateau is no more observed [25, 26].

From this point of view, the local stress-strain behaviour of the ferritic matrix seems to be better described by suppressing the "easy glide" plateau and smoothing the constitutive law of the matrix by extrapolating the classical evolution to the lower values of plastic deformation, thus introducing a "microplastic yield strength" lower than the measured "macroplastic yield strength". This smoothing procedure, which is better physically based, leads to a lowering of the global stress-strain behaviour obtained by numerical modelling $[15,23]$ and gives a good fit with the inverse determination of this stress strain curve using the Gurson's model (Fig. 4).

\section{III.3 Modelling results}

In order to check the validity of the damage parameters and the constitutive equation chosen for the matrix, the mechanical behaviour of smooth and notched specimens has been numerically simulated using the modified Gurson's model. The material failure is taken into account in the modelling. Axisymmetric 8 nodes with reduced integration elements are used for the specimen meshes (figure 5,6 ). In order to model the striction for the smooth specimen a diameter reduction of $5 \%$ is realised in the horizontal symmetric plane.

For the smooth specimen, the calculated stress strain curves can well be compared with the experimental one (figure 7). A very good fit between experience and modelling is found for low plastic deformations, whereas for higher plastic deformations the calculated curve gives lower values than the experimental one. The deformation to failure is overestimated by the model. A better fit between modelling and experience is obtained in notched specimens for the load versus reduction of diameter curve (figure 8). From these two numerical tests it can be concluded that the damage parameters as well as the constitutive equation determined for the matrix appear to be nearly appropriate. The discrepancy between calculated and experimental values of ductility to failure could be due to the heterogeneous distribution of voids (graphite nodules) which greatly influences plastic localisation, especially in smooth specimens. 


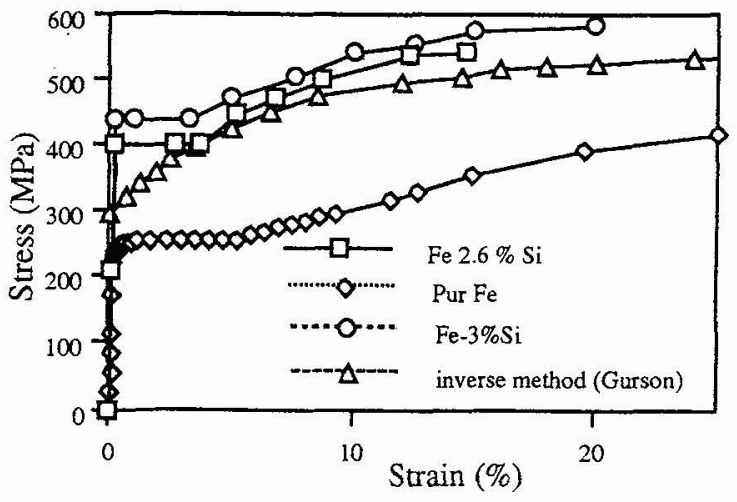

Figure 4. Elastic-plastic behavior of the ferritic matrix

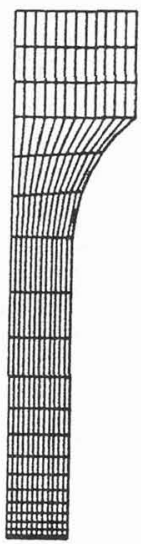

Figure 5. Mesh for the smooth specimen

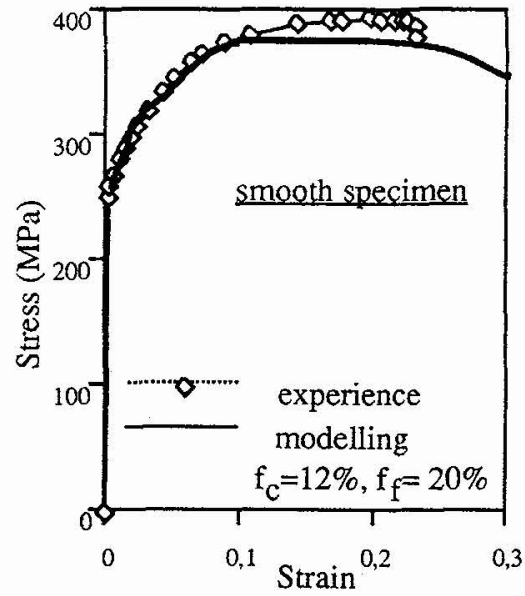

Figure 7. Stress versus strain curves(smooth specimen)

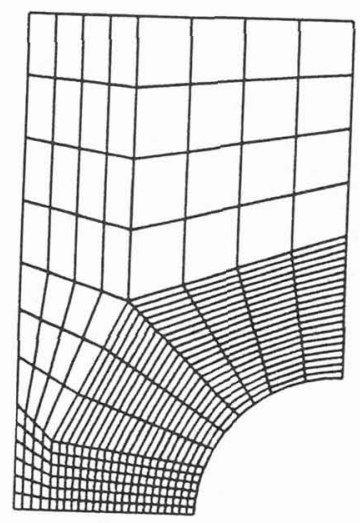

Figure 6. Mesh for the notched specimen

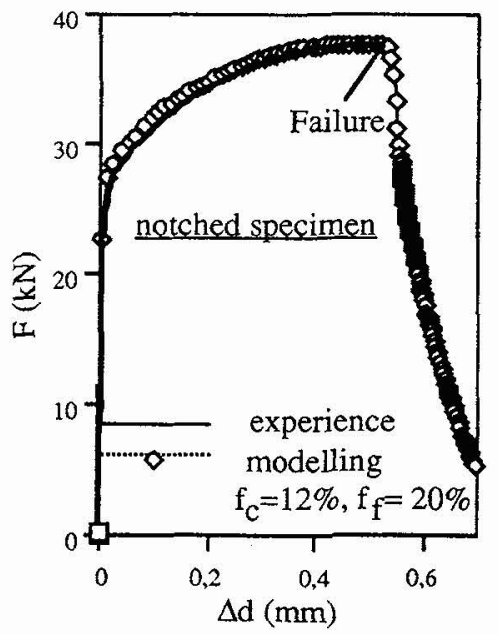

Figure 8. Force versus reduction of diameter (notched specimen) 


\section{Damage modelling ahead of the crack tip}

\section{IV.1 Modelling conditions}

Figure 9 shows the finite element mesh for the CT- 25 specimen. For the $3 \mathrm{D}$ calculations, the thickness is composed of three 20 node elements. To investigate the influence of the stress state hypothesis on the damaged zone extension, plane strain and plane stress conditions were both tested. Crack propagation was considered in this modelling and the precrack length was taken into account. The displacement is imposed, and the boundary conditions are the following : for $y=0$, and $a<x<w, v=0$ ( $v$ and $u$ are the displacement along $x$ and $y$ directions respectively),

at point $A v=0$, at point $B u=U$ prescribed.

By using Gurson's model in the Zebulon code, the plastic zone and damage zone size (defined by $f \neq 0$ ) are calculated for a CT 25 specimen for a crack opening displacement equal to $0.4 \mathrm{~mm}$ which corresponds to crack initiation (table 3 and ref. [17]).

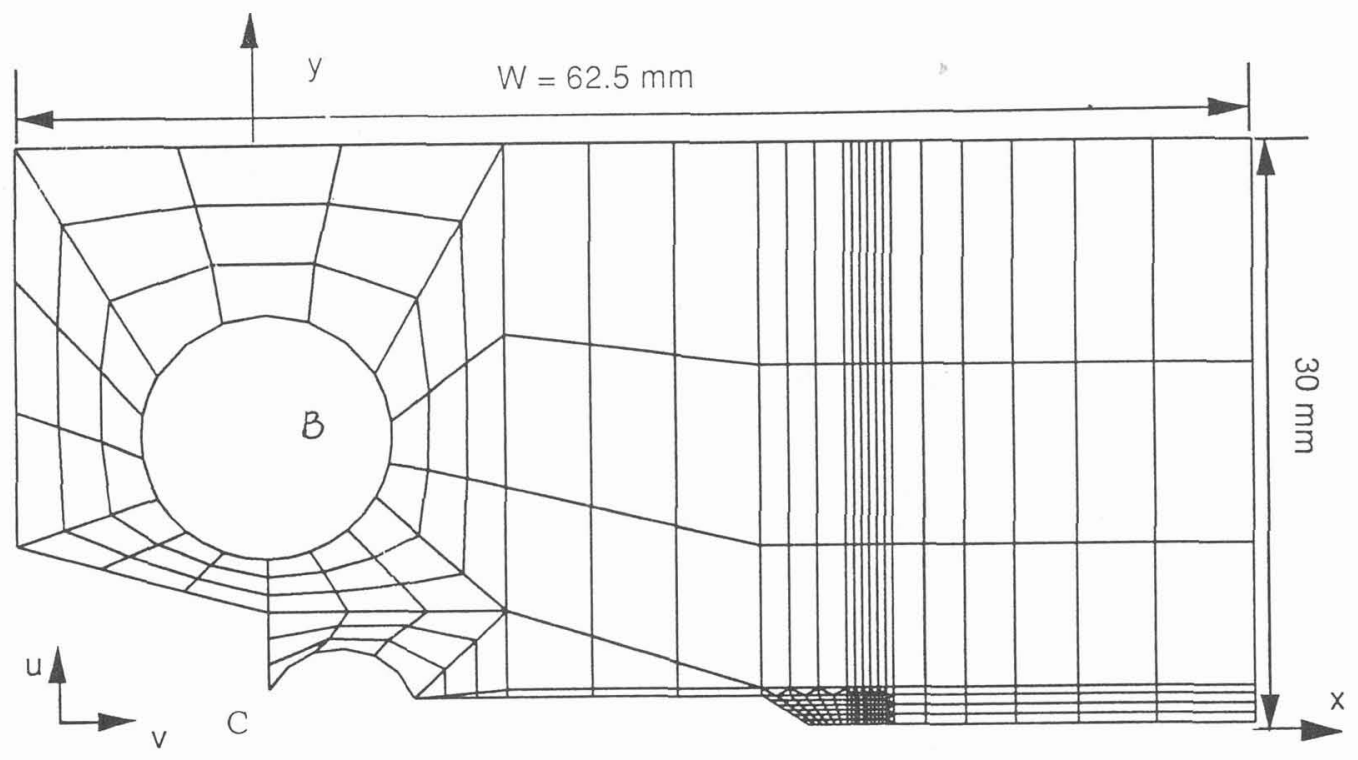

A

Fig. 9- FE mesh of the investigated CT-25 spccimen

\section{IV.2 Modelling of the load versus crack opening displacement curve}

The load versus crack mouth opening displacement curves, calculated for plane strain and plane stress conditions are compared with the experimental one in figure 10 . This figure seems to indicate that, for nodular cast iron, the real stress state ahead of the crack is intermediate between plane strain and plane stress conditions. This result is consistent with toughness studies in porous materials [26] and also with analytical studies about the influence of porosity on plane strain tensile crack-tip stress fields [27].

In order to better understand the stress state at the crack tip in porous materials, the load versus crack mouth opening displacement has been calculated for a CT 25 specimen by $3 \mathrm{D}$ modelling. The result reported in figure 10 shows that the $F-\Delta u$ curve obtained by $3 D$ modelling fits very well with the experimental one, thus confirming our previous conclusions. A modelling using a large displacement formalism should be necessary to extend this result to higher values of the crack opening displacement. 


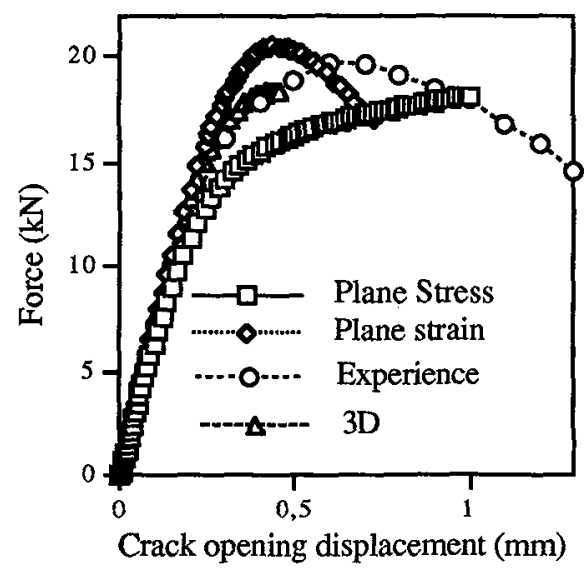

Figure 10. Comparison the modelling curves $F-\Delta u$ in $3 d$ and in $2 d$

\section{IV.3 Damage Evolution}

The damage evolution is followed by the change in the volume fraction of porosity ahead of the crack tip (at Gauss point in the element just ahead of the crack tip). Varying the mesh at the crack tip shows that the mesh refinement exerts a large influence on the damage evolution. The finer the mesh at the crack tip, the earlier the crack propagation is triggered (figure 11). Therefore mesh size refinement was limited to the grain size $(100 \mu \mathrm{m})$, thus preserving the validity of the isotropic hypothesis for the behaviour of the material. Using such a mesh, the evolution of the volume fraction of porosity at the crack tip can be calculated versus CTOD in CT 25 and CT 125 (figure 11). A very good agreement is obtained between the CTOD values calculated for $f_{c}=0.2$ and the values measured by the multiple specimen method at the initiation point $P_{Y}$ (see table 3). Changing the mesh size from 100 to $200 \mu \mathrm{m}$ has a small influence on these results.
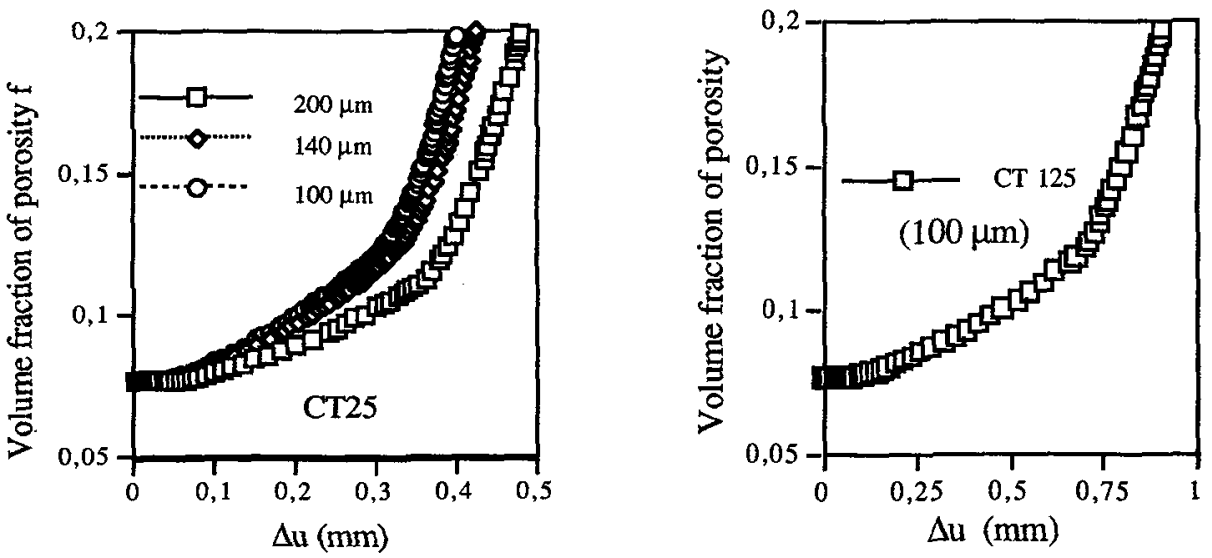

Figure 11. Damage evolution ahead of the crack tip (CT25 et CT 125) 


\section{Discussion}

In order to determine the fracture toughness of cast iron various techniques can be used but, whatever the technique, the definition of crack initiation remains a critical point. $\mathrm{J}_{\mathrm{Ic}}$ can be measured either from the onespecimen method, or from the multiple-specimen method [28]. The initiation of the crack propagation can be defined by $\mathrm{PQ}, \mathrm{P}_{\max }$, the loss of stiffness, or by the R-curve for the multiple-specimen method [29]. The J-integral may be calculated using the standard relationship : $J=\eta A / B b$, where $A$ is the amount of work done, $b$ the uncracked ligament width, $B$ the specimen thickness, $\eta$ a geometry dependent scalar [29].

In order to evaluate the state of damage at $\mathrm{PQ}$, the damaged zone size has been calculated in CT 25 and CT 125 by imposing the crack mouth opening displacement corresponding to $P_{Q}$ [15]. It is shown that for a CT 25, this damaged zone is important as compared with the length of the ligament, so $P Q$ is associated to damage extension rather than to crack initiation. For a CT 125 specimen, the damaged zone remains small as compared with the ligament length so, in this case, the fracture toughness can be obtained using the LEFM approach.

Since matrix graphite interface decohesion induces a large loss of stiffness [16] the methods based on loss of stiffness measurements cannot be used to characterise crack initiation in cast iron.

Finally, this study clearly shows that, in nodular cast iron, the load versus crack opening displacement curve varies with specimen thickness. So the methods usually applied for toughness measurements in dense materials cannot be applied in nodular cast iron for which only the multiple-specimen method is valid. Using this method, no influence of specimen thickness is measured as shown in figure 2.

\section{Conclusions}

Ductile tearing of nodular cast iron CT specimen was simulated numerically by considering nodular cast iron as a porous material. The modified Gurson's model was used for the numerical modelling.

The observations of the damaged zone size show that the extension of the damaged zone is very large in nodular cast iron, through almost the whole ligament ahead of the crack. Consequently, KIc measurements are not valid for small specimens (CT 25).

The stress state in nodular cast iron is intermediate between plane stress and plane strain conditions.

The usual $\mathrm{PQ}$ value characterises damage initiation in small specimens and crack initiation only for large specimens. To obtain the proper value of the fracture toughness of nodular cast iron, the multiple-specimen method, with EPFM approach must be used in small specimens but a procedure using large specimens and the LEFM approach is suggested. The methods based either on $P_{\max }$, or on loss of stiffness are not valid in nodular cast iron.

Nodular cast iron can be treated as a porous material, but its fracture toughness is greater than that of the massive matrix. This result can be attributed to the fact that in nodular cast iron graphite nodules can be considered as voids. These isolated voids gives an enhancement of the plastic zone size owing to the strain softening brought by the early growth of holes.

Acknowledgements : We are grateful to CEA Saclay (DEMT) and Dr. D. Moulin for the authorisation to present the GGG 40 toughness data in this paper. Special thanks are due to Renault Automobiles for the financial support of Mrs Dong. 


\section{References}

[1] Y. Mori, T. Kishi, T. Umeda, D. Sakurai : Transactions, ISIJ, 26 (1986) 277.

[2] R. Salzbrenner, K. Sorenson : AFS Transactions, 137 (1987) 757-764.

[3] S. Mochizuki, H. Matsushita : Nuclear Engineering and Design, 94 (1986) 309-316.

[4] A. Le Douaron, R. Lafont, D. Poulain, C. Cloitre : ICF5, March 29-April 3, 1981, Cannes,

[5] T. Kobayashi, S. Yamada : Metal. Materials Trans. A., 25A (1994) 2427-2437.

[6] B. Ostensson: Scandinavian Journal of Metallurgy, 2 (1973) 194-196.

[7] W. L. Bradley, K. E. M. Kinney, P. C. Gerhardt : Fracture Mechanics, Seventeenth Volume, ASTM STP 905, J. H. Underwood, R. Chait, C. W. Smith, D. P. Wilhem, W. A. Andrews, and J. C. Newman, Eds. American Society for Testing and Materials, Philadelphia, 1986, pp. 75-94.

[8] Nanstad R. K. Nanstand, F. J. Worzala, C.Loper : Trans. AFS., 82 (1974) 473-486.

[9] R. K. Nanstad, F. J. Worzala, C. R. Loper : The metallurgy of cast iron, (ed. B.Lux et al., 1975, St Saphorin, Switzerland, Georgi Publishing, pp. 789-807.

[10] W. L. Bradley, M. N. Srinivasan : International Materials Reviews, 35, n.3 (1990) 129-160.

[11] B. Ostensson: Scand J. Metall. 2 (1973) 194-196.

[12] W. L. Bradley, H. Mead : Cast metals for structural and pressure containement applications. MPC11,1979, pp. 69-87.

[13] W. L. Bradley, H. Mead : Trans AFS., 88 (1980) 265-279.

[14] R. J. Salzbrenner, J. A. Van Den avyle, T. J. Lutz, W. L. Bradley : Fracture Mechanics sixteenth symposium (ed. M. F. Kanninnan and A. T. Hopper), STP 868, 1985, pp. 328-345.

[15] M. J. Dong, B, Tie, A. S. Beranger, C. Prioul, D. Francois : SCI-5, Fifth International Symposium on the Physical Metallurgy of Cast Iron, Nancy, France, October 3-5, 1994 (to be published).

[16] M. J. Dong, G. K. Hu, C. Prioul, D. François : MECAMAT 93, International Seminar on Micromechanics of Materials, Moret-sur-Loing, France, 6-8 July, Eds. EYROLLES, 511-521 (1993).

[17] D. Brouard, S. Foglia, D. Moulin : CEA report, Saclay, 1991, 91/476.

[18] A. L. Gurson : J. Engng. Mater.Tech. , 99 (1977) 2-15.

[19] V. Tvergaard : International J. Fracture : 17 (1981) 389-407.

[20] D. D. Double, A. Hellawell : Proc. 2nd. Int. Symposium on the Metallurgy of Cast Iron, Geneva, 1974, pp. 509-525.

[21] H. Era, K. Kishitake, K. Nagai, Z. Z. Zhang : Mat. Sc. and Tech., 8 (1992) 257-261.

[22] P. Dierickx, C. Verdu, J. C. Rouais, A. Reynaud, R. Fougeres : Fifth Inter. Sym. on the Physical Metallurgy of Cast Iron, Nancy, France, 1994 (to be published).

[23] M. J. Dong, G. K. Hu, A.Diboine, D. Moulin, C. Prioul : Journal de Physique IV, Colloque C7, supplément au Journal de Physique III, 3, novembre, 643-647 (1993).

[24] B. Jaoul : Etude de la plasticité et application aux métaux, Dunod, Paris, (1965) 458.

[25] H. Biausser : Le Livre de l'acier, Eds. Beranger G., Henry G., Sanz G., Technique \& Documentation - Lavoisier (1994).

[26] T. C. Lindley, R. E. Smallman : Acta Metallurgica, 11 (1963) 361-371.

[26] G. Andrews : Powder Metall. group meeting, Country, 5 (1972) 1.

[27] W. J. Dragan, Y. Miao : J. Appl. Mech., 59 (1992) 559.

[28] Standard test method for JIc, measure of fracture toughness Spec. E813-81: 1981, Philadelphia. PA. American Society for Testing and Materials.

[29] E. E. Gdoutos : Fracture Mechanics Criteria and Applications 1991 (Kluwer Academic), pp. 177. 